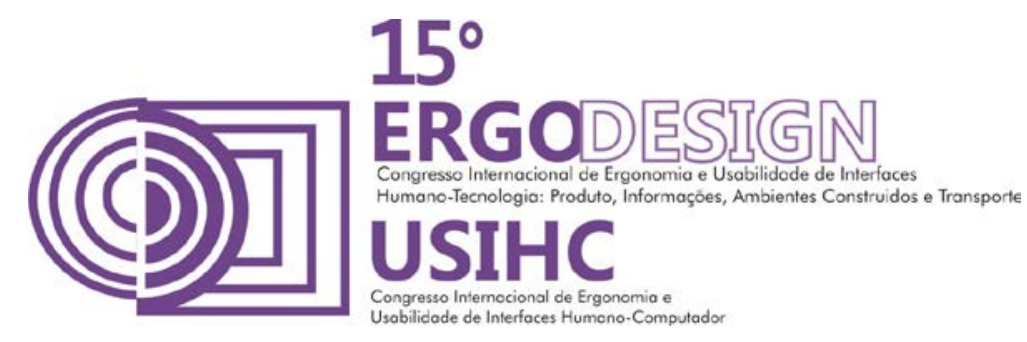

\title{
ANALISE DE INTERFACES VISUAIS APLICADA A AMBIENTES INTERATIVOS: HEINEKEN EXPERIENCE COMO ESTUDO DE CASO
}

\section{ANALYSIS OF DIGITAL INTERFACES APPLIED TO INTERACTIVE ENVIRONMENTS: HEINEKEN EXPERIENCE AS A CASE STUDY}

\author{
BEZERRA, Pablo Felipe Marte (1); \\ ARRUDA, Amilton José Vieira de (2) \\ (1) Universidade Federal de Pernambuco, Mestrando \\ e-mail: pablofelipe81@hotmail.com \\ (2) Universidade Federal de Pernambuco, Ph.D \\ e-mail: arruda.amilton@gmail.com
}

\begin{abstract}
RESUMO
O artigo enfocará no aspecto cognitivo da Ergonomia, especialmente na interação humano-computador (IHC), explorando o impacto que as interfaces digitais têm na criação de experiências únicas para 0 usuário. Será analisada a Heineken Experience, em Amsterdã, um ambiente projetado para mostrar a história da empresa e promover interações diferenciadas. Através de entrevistas com visitantes e dados coletados sobre o local, pretendemos mostrar como o planejamento e gestão de marca aliada a utilização de interfaces digitais, o design focado no usuário e a IHC influenciam na apreciação do visitante ao ambiente e no crescimento da afeição do usuário com a marca.
\end{abstract}

Palavras-chave: Ergonomia Cognitiva, Interação Humano-Computador, Usabilidade, Interfaces Digitais, Design de Experiência, Design Emocional

\begin{abstract}
This article will focus on the cognitive aspect of Ergonomics, especially in the Human-Computer Interaction $(\mathrm{HCl})$, exploring the impact that digital interfaces have on creating unique experiences for the users. It will be analyzed the Heineken Experience, in Amsterdam, a place designed to showcase the company's history and promote exceptional interactions. Through interviews with visitors and collected data about the place we intend to show how planning and brand management combined with the use of digital interfaces, user-centered design and $\mathrm{HCl}$ influence the visitor's appreciation of the environment and in the growth of the user's affection with the brand.
\end{abstract}

Keywords: Cognitive Ergonomics, Human-Computer Interaction, Usability, Digital Interfaces, User-experience Design, Emotion Design 


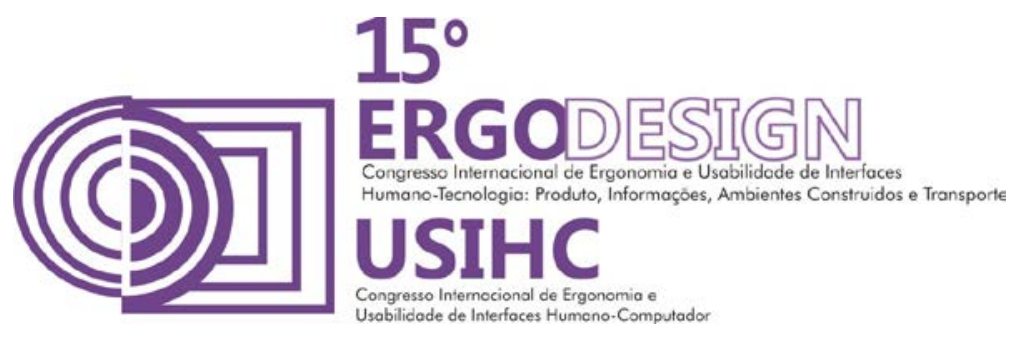

\section{INTRODUÇÃO}

O Homem é um ser transformador e necessita de utensílios para sobreviver em ambientes e condições distintas desde o início dos tempos. Produzir os primeiros abrigos fora das cavernas e inventar objetos como facas, flechas e agasalhos garantiu à raça humana uma superioridade dentre os habitantes da Terra e nos permitiu popular várias regiões do planeta. Se no início os objetos e ambientes eram projetados ao acaso, a partir da tentativa e erro e o aprendizado com as experiências, há algumas décadas nos deparamos com uma realidade onde muitos fatores são considerados na arte de projetar. A figura do Designer surgiu e teorias sobre a forma e função dos objetos foram cunhadas iniciando uma grande discussão que culminou na evolução dos projetos realizados pela humanidade. Segundo Petroski (1992), a evolução dos utensílios interfere de maneira decisiva nos costumes e na interação social e o design aparece para melhor projetar e atender às necessidades da sociedade.

É nesse contexto que atua a Ergonomia, disciplina do Design "relacionada ao entendimento das interações entre os seres humanos e os outros elementos ou sistemas, e à aplicação de teorias, princípios, dados e métodos a projetos a fim de otimizar o bem estar humano e o desempenho global do sistema." (ABERGO - Associação Brasileira de Ergonomia, 2014). Com a evolução da oferta de artefatos, o usuário tornou-se exigente com todos os aspectos que compõe um projeto, sempre avaliando e demandando cuidados especiais relacionados não apenas à estética, mas à funcionalidade e usabilidade dos produtos e exigindo dos fabricantes e projetistas uma constante atenção com suas criações, já que a concorrência acirrada os torna vulneráveis a qualquer deslize. Quando falamos em Ergonomia precisamos entender que ela tem uma dimensão holística, devendo compreender aspectos físicos, cognitivos e socioambientais, sendo assim dividida de acordo com a ABERGO (2014):

- Ergonomia Física: Relacionada com as características da anatomia humana, antropometria, fisiologia e biomecânica;

- Ergonomia Cognitiva: Refere-se aos processos mentais, tais como percepção, memória, raciocínio e resposta motora conforme afetem as interações entre seres humanos e outros elementos de um sistema;

- Ergonomia Organizacional: Concerne à otimização dos sistemas sóciotécnicos, incluindo suas estruturas organizacionais, políticas e de processos.

Desde sua invenção em meados do século $X X$ o computador vem se tornando cada vez mais importante no cotidiano de todos, expandindo seu uso para muito além dos fins militares e matemáticos que impulsionaram sua criação. Com o surgimento dos PCs, os computadores pessoais, na década de 70, iniciou-se um crescimento exponencial da aplicabilidade de sistemas computadorizados no dia-a-dia da sociedade e atualmente encontramos módulos inteligentes em objetos e ambientes variados, como celulares, eletrodomésticos e espaços interativos projetados para promover momentos diferenciados ao consumidor. Nesse processo, cresceu também a importância de observar a forma como as pessoas interagiam com esses dispositivos a fim de projetar e aperfeiçoar os artefatos com ênfase na usabilidade, que segundo Nielsen (1993) compreende a facilidade que o usuário tem para aprender a utilizar o artefato, a eficiência do sistema, capacidade de memorizar como o produto deve ser manuseado, baixa taxa de erros na operação do sistema e satisfação no uso do mesmo. 


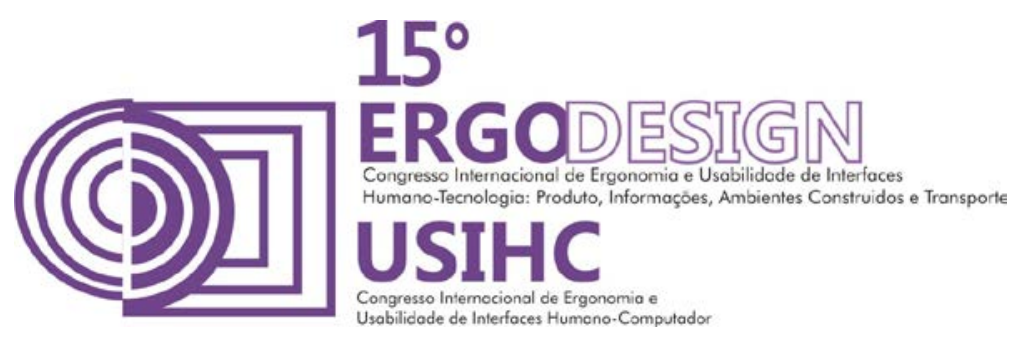

Atualmente, muitas interfaces digitais são utilizadas no mercado para criar uma interação entre os consumidores e as empresas e tais plataformas podem propiciar experiências únicas. A popularização de tecnologias de Realidade Virtual (RV), por exemplo, torna possível a criação de momentos e ambientes que permitem que as marcas se comuniquem mais profundamente com os seus clientes, explorando aspectos emocionais e sensoriais que ajudarão a estabelecer um forte elo entre as duas partes.

Uma das maiores cervejarias do mundo, a Heineken é uma empresa que consegue aliar tradição e inovação, hoje consolidada como uma das grandes marcas do planeta. Como parte de uma grande estratégia de gestão de marcas, ou branding, a empresa construiu em Amsterdã um espaço que traz elementos de fábrica, museu, bar e centro de entretenimento, tornando-se um dos principais pontos turísticos da cidade e parada obrigatória para todos que visitam na capital holandesa. Contando com várias atrações, a Heineken Experience se destaca pelo uso de plataformas digitais para promover experiências interessantes para os visitantes e tornar 0 passeio algo realmente único, consolidando a força da empresa junto aos seus clientes.

\section{CONTEÚDO}

\subsection{Fundamentação}

Conforme citado na introdução deste trabalho, a Ergonomia estuda a interação entre os seres humanos e os sistemas, buscando uma melhor adaptação dos projetos às necessidades e características dos usuários. Segundo Dul e Weerdmeester (2012) o seu desenvolvimento deuse na II Guerra Mundial, com a conjugação sistemática de esforços entre a tecnologia, ciências humanas e biológicas para resolver problemas de projeto. Ainda conforme os autores, tal envolvimento interdisciplinar trouxe resultados satisfatórios a ponto de serem aproveitados pela indústria no pós-guerra, em especial na Europa e Estados Unidos. Vale ressaltar, no entanto, de acordo com Láuar et al. (2010), que os estudos ergonômicos iniciaram-se bem antes desse período, ainda no Renascimento com Leonardo Da Vinci (1542) e tendo evoluído com Ramazzini (1700), Jastrzebowski (1857), Taylor (1903), Gilbreth (1900) entre outros, sendo esta fase denominada de ergonomia precursora ou gestacional.

Como foi mencionado nesse artigo, abordaremos a ergonomia cognitiva, relacionada com os aspectos mentais, como percepção e memória do usuário: "teve um impulso nos anos 1980 com o advento do computador e a maioria dos estudos dizia respeito às características da interface ou da interação humano-computador enfatizando os aspectos semânticos e cognitivos da informação que aparece na tela." (CARVALHO, 2011). Primeiramente, faz-se necessário entender o que é a cognição e qual a sua relação com a ergonomia e o seu papel na construção de um design considerado de sucesso. Segundo Cañas e Waerns (2001), entendemos "cognição" como o obter, manter e usar o conhecimento, porém é necessário enxergar o conceito de forma mais ampla. De acordo com os autores, se falamos do conhecimento que uma pessoa tem estamos nos referindo à cognição mental, já se o que nos interessa é como as pessoas compartilham e comunicam tais informações tratamos da cognição comunicativa. Por fim, se falamos da transferência de conhecimento de uma pessoa para um artefato estamos nos referindo à cognição distribuída. Sendo assim, "para realizar uma tarefa uma pessoa tem que perceber estímulos do ambiente, receber informação de outras pessoas, decidir que ações são apropriadas, transmitir informações a outras pessoas que 


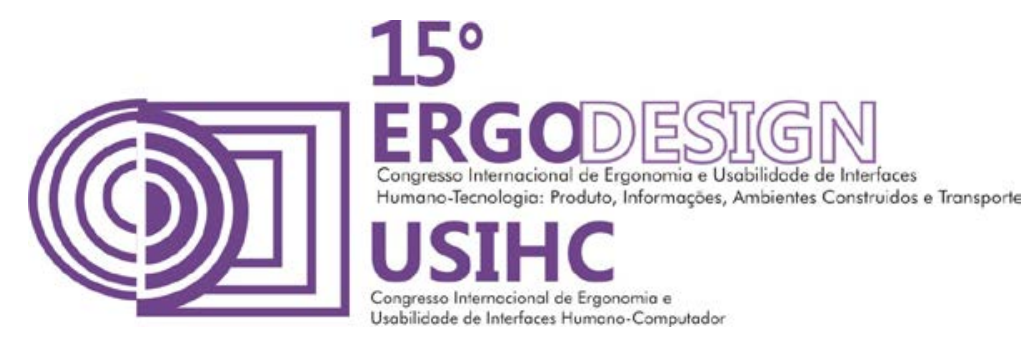

podem realizar a tarefa, etc. Todos esses aspectos são o objeto de estudo da ergonomia psicológica ou cognitiva." (CAÑAS; WAERNS, 2001).

De fato quando idealizamos um sistema bem sucedido de interação com o usuário, todos os aspectos cognitivos devem ser considerados, uma vez que formam o repertório intelectual do indivíduo. Assim, cada vez mais a Ergonomia observa outros domínios, - além dos aspectos físicos, organizacionais e cognitivos anteriormente citados - a usabilidade, que é o estudo específico para a ciência da computação e tem como objetivo facilitar o uso dos sistemas computacionais, e a acessibilidade, que pesquisa as necessidades especiais para tornar produtos e ambientes "amigáveis" ao maior número de usuários (SOARES; DA SILVA; PASCHOARELLI, 2013) para buscar tão sucesso na elaboração dos projetos.

\subsection{Interação Humano-Computador $(\mathrm{HCl})$ e Usabilidade}

As tecnologias de informação e comunicação (TICs) vêm evoluindo exponencialmente ao longo das últimas décadas. Se há 20 anos obter uma linha telefônica ou comprar um computador pessoal (PC) era para poucos, hoje indivíduos de todas as classes sociais, idades e localização geográfica têm largo acesso a smartphones, tablets e vários outros dispositivos (gadgets), comunicando-se com seus pares de várias formas como telefone, e-mail, mensagens e vídeo conferência de forma rápida e acessível. Além dos meios de comunicação, vários outros objetos contam com sistemas computadorizados, como máquinas fotográficas que reconhecem a luminosidade e se adaptam às condições do momento, geladeiras e fogões inteligentes que conversam e gravam as preferências dos seus usuários, carros que não precisam mais de chaves para ser abertos ou ligados, dentre outros produtos que mais parecem saídos de filmes de ficção científica.

A popularização das TICs permitiu uma maior integração entre as pessoas de várias partes do mundo e as tornou mais ávidas e exigentes quando falamos de inovações tecnológicas. Barbosa e Silva (2010) afirmam que as TICs estão revolucionando a área de entretenimento, com jogos eletrônicos interativos, a TV digital interativa (TVDI), que permite ao usuário escolher o que assistir, gravar os seus programas favoritos e até participar de enquetes a partir do seu controle remoto, e promovendo comodidade aos usuários, como por exemplo na compra de ingressos para o cinema via celular. Outras áreas, como a educação, também têm se beneficiado com o maior acesso à tecnologia. Professores e instituições fazem cada vez mais fazem uso da internet para suas pesquisas e aulas, oferecendo aos seus alunos formas alternativas de acesso ao conhecimento, como, por exemplo, os jogos educativos que são um grande sucesso e têm sido uma das principais atividades de designers e profissionais da informática atualmente. "Diferentemente de outras mídias como o papel e quadro negro, as TICs permitem criar materiais dinâmicos e interativos que podem favorecer o aprendizado, como vídeos, simulações de fenômenos naturais, exploração de realidades virtuais, comunicação e colaboração entre alunos e professores com apoio computacional, e assim por diante." (BARBOSA; SILVA, 2010). Outros setores como a política, através de portais de transparência e do uso das redes sociais, o comércio e o transporte fazem uso constante das inovações tecnológicas e influenciam diretamente no cotidiano da sociedade.

Dentro desse contexto, o designer como criador de interfaces tem um papel importante para a concepção de produtos e ambientes que promovam uma interação satisfatória com o usuário. "Uma preocupação crucial do design de interação é desenvolver produtos interativos que sejam 


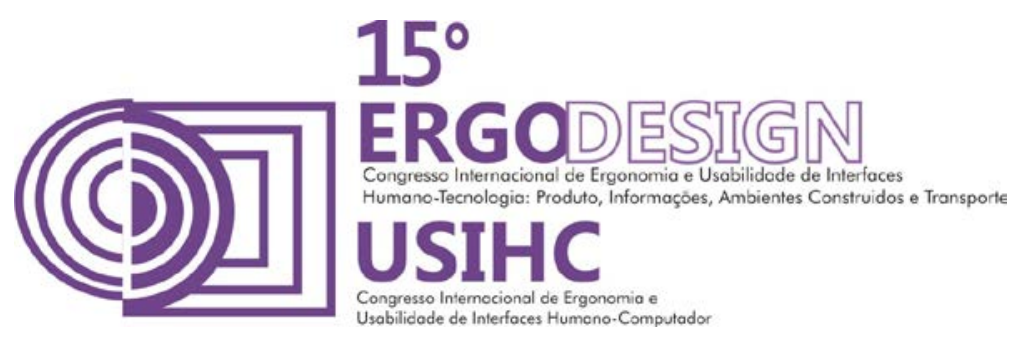

usáveis, o que genericamente significa produtos que sejam fáceis de aprender a usar, eficazes e que proporcionem ao usuário uma experiência agradável." (CHAPMAN, 2011). Utilizando de conhecimentos ergonômicos e explorando os aspectos sensoriais dos indivíduos é possível proporcionar experiências diferenciadas e que serão lembrados pelas pessoas de forma satisfatória. É necessário ressaltar, no entanto, que da mesma forma podem causar um efeito positivo, um design que não tenha sucesso na busca pela boa interação pode trazer um consequência igualmente negativa, acabando por ser maléfica à imagem da empresa, sendo, portanto, de suma importância o conhecimento do perfil de quem estará utilizando os artefatos a fim de buscar uma melhor usabilidade. De acordo com Nielsen (1993) a usabilidade depende muitas vezes de pequenos detalhes, e é por isso que um trabalho sistemático de engenharia da usabilidade é importante para trazer esses detalhes à tona.

\subsection{Interfaces Digitais e Realidade Virtual}

Para entender o papel da ergonomia na concepção de sistemas de interação bem sucedidos é necessário inicialmente compreender o conceito de interface. De acordo com Coelho (2008) a interface "[...] indica a possibilidade de adaptação, de interconexão, de comunicação entre dois ou mais sistemas, equipamentos, unidades, etc. [...] a interface de um sistema em que se faça a interação humana é tratada pelo design através da ergonomia.". É possível notar, através da conceituação apresentada, que interface trata da relação entre o usuário e o sistema, seja ele um produto, um componente ou um ambiente. É papel do designer projetar um artefato e assegurar que quem for utilizá-lo consiga navegar pela sua estrutura e entender qual a função de cada elemento. Em uma TV, por exemplo, deve ficar claro onde deverão ser conectados os fios, onde conseguiremos mudar de canal ou aumentar e diminuir o volume. O cuidado com a criação de uma interface vai ser determinante para avaliar o grau de usabilidade do produto, influenciando diretamente no seu sucesso frente ao mercado.

Hoje, porém, mais do que projetar botões e conectores, os designers criam interfaces digitais que permitem aos usuários interagir com os sistemas de forma mais direta. Segundo Chapman (2011) o design de interface do usuário encontra-se, juntamente com o design de experiência, o design centrado no usuário, o design de sistemas interativos e o design de produto, dentro do guarda-chuva do Design de Interação, onde "o foco [...] é na prática [...] criar experiências de usuário.". Podemos ver claramente essa tendência nos automóveis, por exemplo, e seus computadores de bordo, em eletrodomésticos inteligentes e até em ambientes projetados, como museus, onde a visita é guiada por dispositivos eletrônicos que auxiliam na passagem de informações aos visitantes e promovem uma interação diferenciada, enriquecendo ainda mais a experiência do usuário.

Uma das formas encontradas para gerar essa diferenciação nas vivências em ambientes projetados é a Realidade Virtual (RV), que cria reproduções "aceitáveis" de objetos ou ambientes reais para treinamentos, entretenimento ou propósitos de design (THALMANN; VEXO; GUTIERREZ, 2008). De acordo com Falcão e Soares (2013), as tecnologias que incorporam a realidade virtual começaram a ser desenvolvidas nos anos sessenta, tornando-se disponível para o uso industrial nos anos noventa. Ainda segundo os autores, "a partir dos vários dispositivos periféricos, tais como sistemas de captação de movimentos e interfaces táteis, fornece um ambiente de trabalho imersivo com diferentes maneiras para a interação entre o usuário e o sistema. Thalmann, Vexo e Gutierrez (2008) afirmam que o objetivo principal 


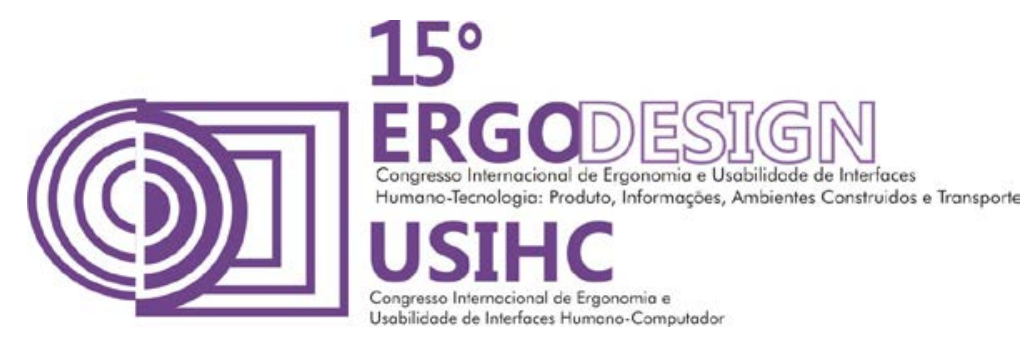

da RV é criar no usuário a ilusão de estar em um ambiente percebido como crível com interatividade suficiente para realizar tarefas específicas de forma eficiente e confortável. É possível perceber que a concepção de experiências contendo RV e outras interfaces digitais em um ambiente bem planejado desperta nas pessoas um elevado grau de curiosidade $\mathrm{e}$ engajamento, podendo trazer resultados bastante satisfatórios garantindo, assim, a boa impressão da visita e uma posterior propagação das sensações experimentadas aos amigos e familiares que, provavelmente, também buscarão conhecer os efeitos descritos.

\section{$2.4 \quad$ User Experience Design}

O design de experiência, ou o User Experience Design (UXD), é "[...]uma coleção de métodos aplicados ao processo de design de experiências interativas. Encoraja o designer a tornar a qualidade da experiência do usuário a principal preocupação." (ALLANWOOD; BEARE, 2014). Em uma realidade onde os produtos e serviços têm cada vez menos diferenciação entre si, as empresas têm aprendido que o consumidor deve ser o seu grande foco e é preciso entender não apenas o que ele necessita, mas como ele pensa, o que faz, com quem convive e o que lhe deixa satisfeito. É compreendendo o seu interior que podemos prever e fornecer aquilo que será considerado como valioso para a sua vida agora e no futuro, sendo esse um passo crucial em busca da vantagem competitiva. Segundo os autores, para idealizar um design de experiência bem sucedido é necessário um forte trabalho de equipe, uma vez que aquilo que será considerado como uma boa experiência não está aparente e necessitará de conhecimentos de áreas distintas, além de ser indispensável considerar restrições de tempo, orçamento e outros recursos.

Para tanto, precisa-se olhar cada vez mais para dentro de cada usuário e enxergar as suas verdadeiras emoções e o que os motiva em diversos aspectos de sua vida. De acordo com Norman (2005), o Homem tem atributos mentais que o separa dos demais animais e que a nossa capacidade criativa aliada a nossa consciência e habilidade de aprender novas coisas nos faz lidar com situações de forma diferenciada. Segundo o autor, esses atributos resultam de três níveis diferentes em nosso cérebro. O visceral, responsável por nossas reações automáticas - sendo a camada mais superficial -, o nível comportamental, parte que contém os processos que controlam nosso comportamento usual, e a mais profunda região, o nível reflexivo, que considera nossa capacidade mais intelectual e pensativa. Todos esses elementos formam o nosso intelecto e influenciam as nossas ações, sejam elas as mais simples, como fugir de uma superfície demasiadamente quente, ou complexa como decidir entre um produto e outro, uma marca em detrimento de outra. E é reconhecendo e considerando tanta complexidade - definida por Cardoso (2011) como "um sistema composto de muitos elementos, camadas e estruturas, cujas inter-relações condicionam e redefinem continuamente 0 funcionamento do todo." - em nosso comportamento que as empresas podem utilizar do design de interação e todas as suas ramificações para promover vivências que comuniquem com seus usuários da forma mais profunda possível, já que "[...] uma pessoa interpreta uma experiência em vários níveis, mas o que apela a um deles pode não apelar a outro. Um design de sucesso deve atingir a todos os níveis." (NORMAN, 2008, tradução nossa).

Quem consegue atingir níveis tão profundos, cria no consumidor uma sensação forte de satisfação e confiança, que ele vai carregar por muito tempo, isso se a empresa compreender que essa é a chave para assegurar um sucesso sustentável, garantindo a busca constante por 


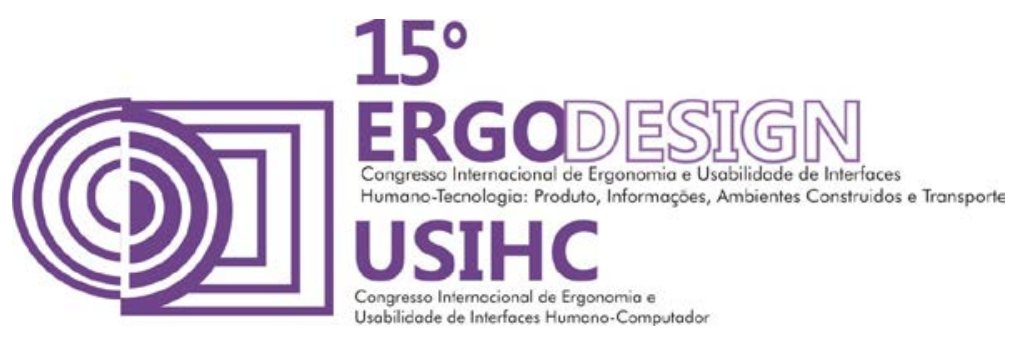

excelência através do UXD e transformando o usuário em muito mais que um cliente, mas um verdadeiro admirador da marca e dos valores cultivados por ela. Segundo Norman (2008), existe um fator que age diretamente nos 3 níveis do nosso intelecto - o tempo. O autor diz que as faces visceral e comportamental do cérebro estão ligadas ao "agora", aos seus sentimentos e experiências relacionados à visualização e utilização dos produtos, sistemas ou ambientes. Já o nível reflexivo está relacionado aos aspectos de longo prazo, já que através da reflexão nos lembramos do passado e contemplamos o futuro. Traduzir esses elementos intangíveis por meio dos artefatos, sistemas e ambientes é o papel da equipe de design e toda a sua interdisciplinaridade, hoje verificada como característica marcante para a melhor visualização de todo o cenário em que o desafio está inserido. "Designers precisam considerar o impacto de sua atividade nas pessoas para quem eles estão projetando e criar trabalhos que mostram a compreensão de suas necessidades." (ALLANWOOD; BAERE, 2014, p. 16, tradução nossa).

Conseguimos visualizar atualmente a aplicação de tais conceitos de várias formas nas ações de relacionamento das marcas com os consumidores. Segundo Arruda (2013), as experiências de uma marca não são exclusivas do espaço digital. "Como exemplos de negócios embasados em experiência podemos citar os parques temáticos da Disney ou mesmo a cidade temática construída pela Volkswagen na Alemanha, as lojas Sony Style, da Sony, e a Apple Store de Nova York, São Francisco e Londres." (ARRUDA, 2013). O que esses locais têm em comum é a imersão dos consumidores através de experiências interativas e um projeto de design focado em suas necessidades e desejos, evocando muito mais do que aspectos estéticos ou funcionais, mas implementando emoção em tudo o que compõe os espaços, incluindo sua iluminação, uso de cores e sons, e um grande cuidado com o uso de peças comunicativas, a ergonomia e usabilidade do espaço.

Outro exemplo famoso de espaço interativo, desenvolvido a partir de ferramentas de UXD é o estudo de caso do presente artigo, a Heineken Experience, museu e centro de entretenimento da cervejaria holandesa Heineken, em Amsterdã.

\subsection{Case de Estudo}

Fundada em meados do século XIX por Gerard Adriaan Heineken a partir da compra de uma pequena cervejaria situada em Amsterdã, na Holanda, a Heineken é hoje uma das principais marcas do mundo e, certamente, um dos maiores fabricantes de cerveja do mercado. Já no inicio da sua história, a cervejaria primou por fomentar a inovação, o que garantiu a ela não apenas uma fórmula diferenciada - que se mantém ao longo de toda a sua história - mas um grande destaque no seu segmento, sendo premiada em 1875 com a "Medaille Do'r" em Paris e recebendo em 1889 "Diplome de Grand Prix" na World's Fair, realizada também na capital francesa, feitos que são relembrados no rótulo do produto até hoje. Sua capacidade inovadora também pôde ser observada na sua estratégia de negócio, com a sua expansão internacional, chegando à África em 1900, à Ásia em 1929 e aos Estados Unidos em 1933 quando, após o fim da Lei Seca que vigorava no país, tornou-se a primeira cerveja importada na América.

Ao longo de sua história a empresa mostrou-se sempre comprometida a "viajar" e explorar o mundo, levando suas tradições e fazendo da Heineken uma marca de impacto e representatividade junto ao público. Para tanto foram feitas aquisições, como da sua maior rival, a Amstel, no fim dos anos 1960, e formuladas estratégias de marketing poderosas, tornando-se bastante popular ao redor do mundo. Hoje encontramos a logomarca da empresa patrocinando 


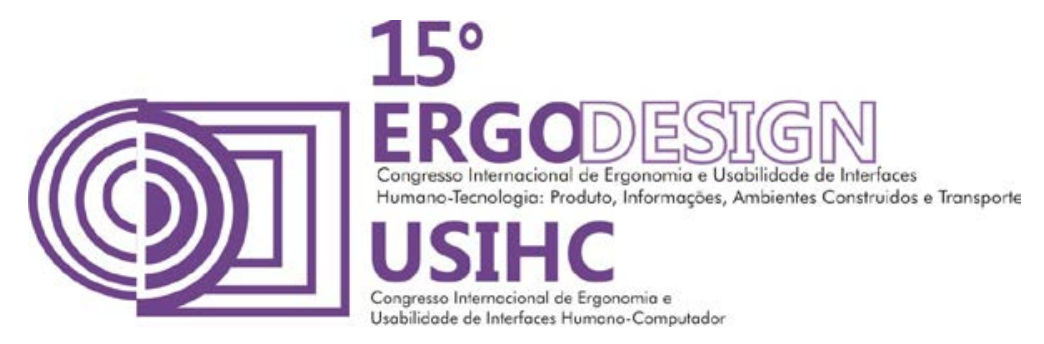

eventos importantes como a UEFA Champions League, maior campeonato de clubes de futebol da Europa, e o Rock in Rio, e presente em mais de 70 países com outras marcas abaixo do seu "guarda-chuva", como a Sol, a Desperados (onde inovou com uma mistura entre cerveja e tequila), e a já mencionada Amstel, que foi mantida mesmo após sua compra.

A empresa se destaca por uma preocupação constante com o design. Contando com um rótulo icônico, outro elemento de destaque no produto é a sua tradicional garrafa verde, que a diferencia da grande maioria de suas concorrentes. Também inovou com a criação de novas embalagens como o barril de $5 \mathrm{~L}$ e mais recentemente o THE SUB, elaborado em parceria com designer Marc Newson, e várias formas de expor a marca. Uma das mais atuais e interessantes é a igNITE, um acessório desenvolvido especialmente para adicionar luminosidade à garrafa e torna-la destaque em eventos e festas. Aliás, a empresa reserva em seu site um espaço direcionado à inovação, encorajando os pesquisadores a desenvolver avanços relacionados à fabricação, embalagens, forma de servir etc.

Como parte de um plano estratégico e de marketing exemplar, a empresa inaugurou em 2001, onde funcionava a sua primeira fábrica que havia sido desativada em 1988, um espaço projetado especialmente para contar a sua história e mostrar a todos a força e qualidade da cerveja, a Heineken Experience. Com 4 andares de "experiências interativas", como descreve o site HeinekenCompany.com, o prédio conta com um museu, salas de eventos e reuniões, uma BrandStore onde são comercializados vários produtos licenciados, um estábulo - já que a empresa considera os cavalos uma parte importante de sua história por sua importância logística e caráter de embaixadores da marca -, bares e uma série de atrações interativas, que incluem salas recheadas de telões com muita luz e música, projeções em 4D que mostram o processo produtivo aos "olhos de uma cerveja" e várias outras atrações que convidam o público a fazer parte da experiência Heineken. Ainda, um aplicativo de celular foi desenvolvido para iOS e Android, contando com versões em 9 idiomas, que mostram um pouco das instalações e da história dessa grande marca e desse espaço criado para celebrar a Heineken junto ao público.

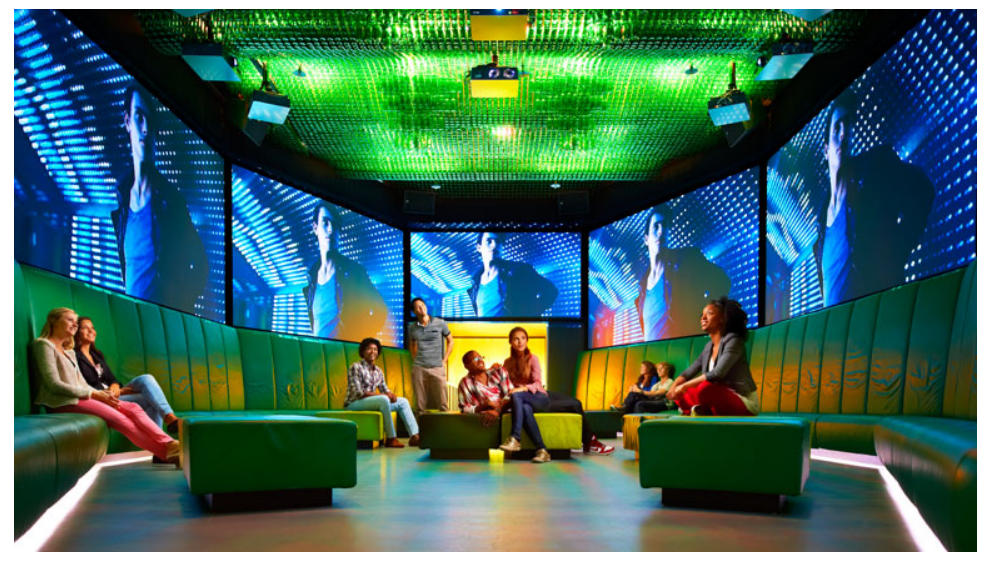

Figura 1 - Espaço para visualização de propagandas da Heineken

Com uma passada rápida no site e nas redes sociais da Heineken é possível observar o quão impactantes são as experiências interativas oferecidas na Heineken Experience. Seja tirando uma foto segurando uma versão virtual do troféu do Campeão Europeu de Futebol, "conversando" com um mestre cervejeiro através de um vídeo ou ainda vivenciando toda a 


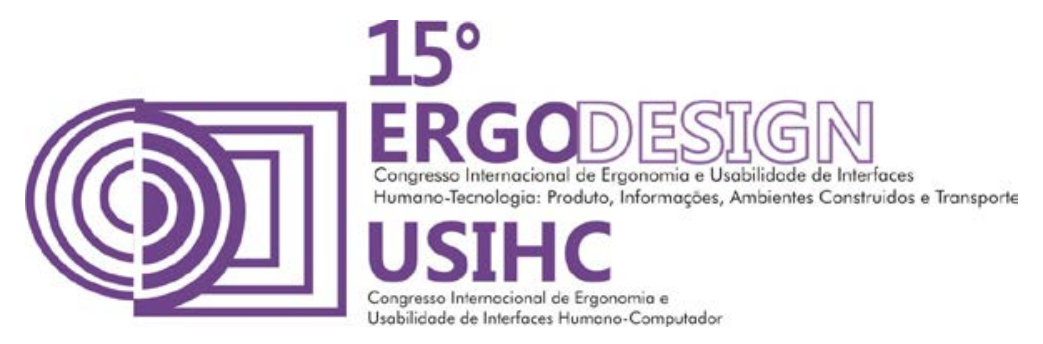

cadeia produtiva através de uma exibição em 4D, a Heineken proporciona aos visitantes do local sensações que marcam profundamente e tornam o passeio inesquecível, cativando mesmo aqueles que não são ávidos consumidores de seus produtos. Em entrevistas com alguns visitantes, algumas dessas experiências puderam ser comprovadas: "Após passarmos pela antiga fábrica visitamos um cinema 4D que mostra o processo de fabricação como se fôssemos uma cerveja. Você balança, cai na água, é muito divertido. Em seguida entramos em uma sala muito bacana onde são exibidas várias campanhas publicitárias da empresa, que sempre são interessantes, e em seguida vamos a outro ambiente onde existem vários jogos interativos e opções de divertimento." O relato da visitante mostra que visitar a Heineken Experience vai muito além de conhecer a história ou tomar algumas cervejas, mas as atrações cuidadosamente pensadas, com vários elementos digitais, e todo o cuidado do design do ambiente tornam a experiência realmente única.

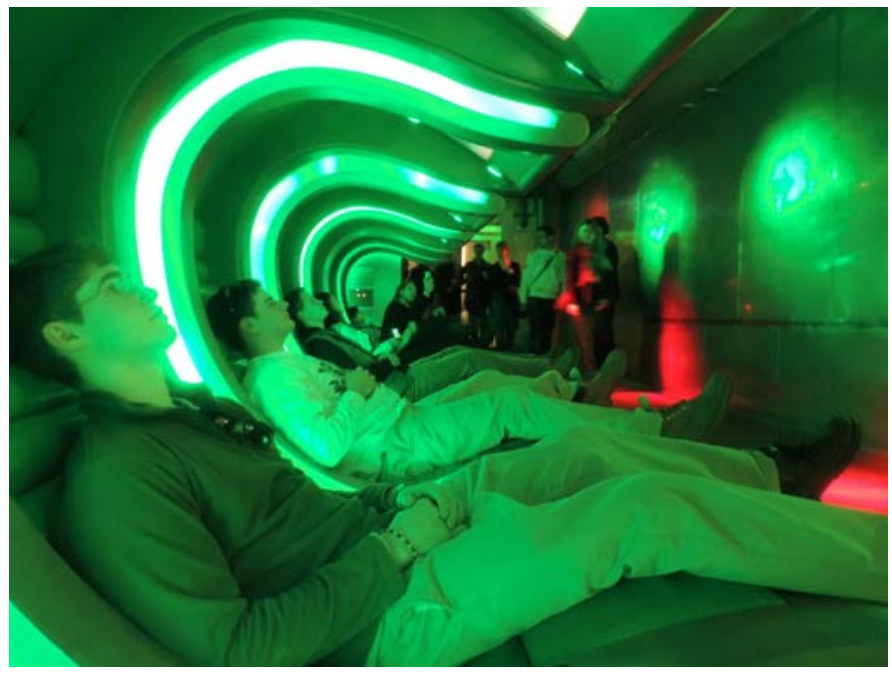

Figura 2 - Projeção em 4D do processo de fabricação da Heineken

\subsection{Emotion Design}

Uma marca é um "nome, termo, desenho, símbolo ou qualquer outra característica que identifique um bem ou serviço de um determinado fabricante como diferente dos de seus concorrentes." (American Marketing Association, 2014, tradução nossa). Mais do que os aspectos retratados na conceituação acima, uma marca deve representar a identidade de uma empresa ou produto, seus valores e comunicando ao consumidor quais os benefícios que podem ser obtidos com a compra daquele bem. Dessa forma, é muito importante que a empresa tenha total consciência do que compõe o seu DNA, o que a torna diferenciada perante os concorrentes, e utilize das ferramentas estratégicas adequadas para transmitir isso ao consumidor. Como afirma Kotler (2006) "As empresas atendem as necessidades emitindo uma proposta de valor - um conjunto de benefícios que oferecem aos clientes para satisfazer suas necessidades. A proposta de valor intangível é materializada por uma oferta, que pode ser uma combinação de produtos, serviços, informações e experiências. Uma marca é uma oferta de fonte conhecida.". 


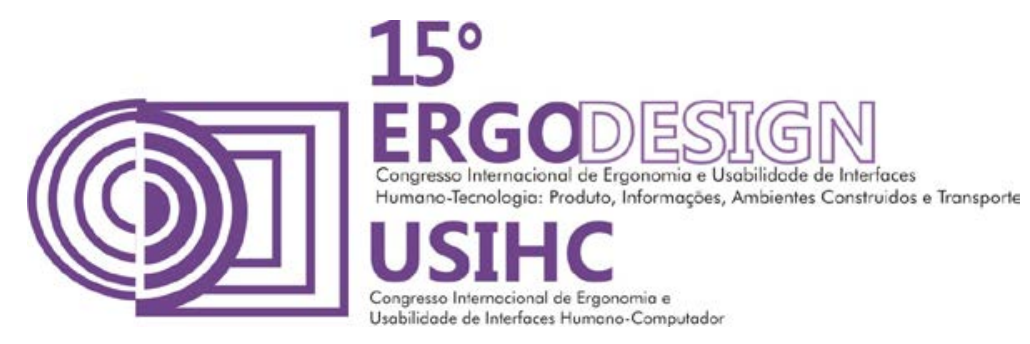

Quando Kotler fala de "fonte conhecida" ele refere-se a uma segurança do consumidor sobre a procedência daquele bem que ele estará adquirindo. Uma vez que estará investindo recursos, seja dinheiro, tempo ou qualquer outro, é importante que ele saiba que estará recebendo aquilo que é esperado daquele artefato, serviço ou ambiente, e a marca é o principal indicador dessa origem. Por essa razão que hoje as organizações têm consciência de que devem cuidar de suas marcas como o seu principal ativo, entendendo que elas podem ser responsáveis por levá-las ao topo ou ao abismo. $\mathrm{Na}$ atual conjuntura do mercado, encontramos consumidores cada vez mais cientes do que os rodeiam. A evolução das TICs, como já mencionado neste trabalho, transformou a realidade dos negócios com uma disseminação de informações praticamente instantânea entre todos os atores do processo. Um consumidor tem acesso fácil a toda a história, características e notícias dos fabricantes e seus produtos e utilizam-se disso para serem cada vez mais exigentes. Isso acontece pois eles sabem que têm o poder de influenciar a muitas outras pessoas e que a tecnologia hoje permite que eles sejam ouvidos facilmente. Com a popularização da internet e das redes sociais, qualquer consumidor pode construir ou destruir uma marca em poucos cliques e esse é um grande poder que as empresas devem reconhecer e respeitar, primando assim, acima de tudo, pela qualidade de seus produtos e serviços e a sua relação com seus clientes.

Por essa razão, cada vez mais as marcas devem buscar estabelecer uma conexão emocional com seus consumidores, que as percebe de forma diferenciada com o devido trabalho de imagem. Elas "[...] assumem destaque nas relações de compra e venda, indo além da ideia de meras facilitadoras das transações comerciais para transformar-se em poderosos e complexos signos de posicionamento social e de ser no mundo." (PEREZ, 2004). Elas têm o poder de representar sentimentos profundos e serem "convidadas" a compartilhar os momentos importantes junto aos seus clientes. No caso da Heineken, a empresa vem trabalhando um posicionamento bem definido junto ao público jovem de todas as partes do mundo. Seus investimentos em grandes eventos, um design inovador em todas as suas esferas e a consciência e cultivo da sua relação com o usuário é clara e isso reflete diretamente em seu posicionamento no mercado. Presenciei, por exemplo, no Rock in Rio, em 2011, um grande entusiasmo do público em descer na "tirolesa da Heineken", o que podia ser evidenciado nas grandes filas que os fazia até "perder" um ou outro show em troca da experiência promovida pela empresa de voar à frente do palco e viver um momento inesquecível. Quando uma marca entende que ser responsável por proporcionar experiências desse nível impacta tanto ou mais do que intervenções no produto em si ela sabe que encontrou o caminho para ser relevante e inovadora mantendo as suas tradições, afinal por que gastar recursos absurdos tentando mudar algo que funciona quando o que o usuário quer de verdade é ter sua personalidade compreendida e viver a vida da forma mais espetacular possível?

As grandes organizações têm entendido o recado e buscam cada vez mais ouvir os anseios dos seus clientes e atende-los da melhor forma sem esquecer-se de deixar claro para todos de que essa atitude é uma parte crucial de seu compromisso com o mercado. Nesse processo o Marketing, que segundo Kotler (2006) trabalha com a identificação e satisfação das necessidades humanas e sociais, tem evoluído e hoje encontramos uma nova filosofia sendo cada vez mais cultivadas nas grandes empresas, a gestão cuidadosa de suas marcas ou 0 Branding.

3 CONCLUSÃO 


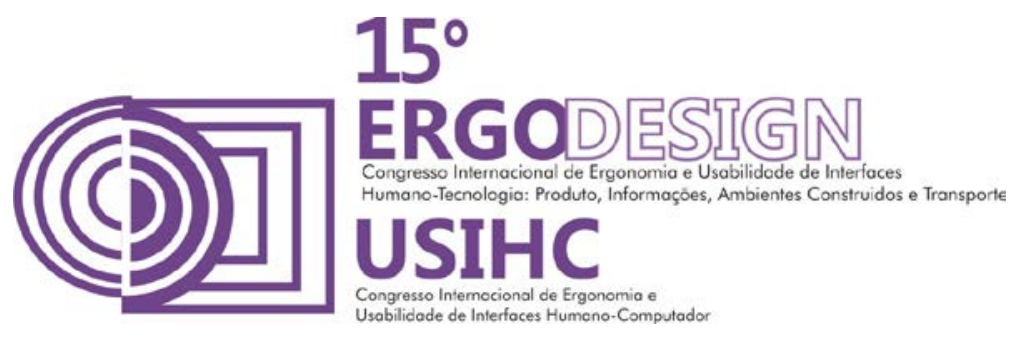

A Ergonomia costuma ser associada aos seus aspectos físicos, mas vai muito além disso. Projetar algo buscando a melhor adequação àquele que irá utilizá-lo carece de uma observação ampla do que envolve a utilização do projeto por parte do usuário e as suas características e possíveis limitações. O estudo da ergonomia cognitiva proporciona um direcionamento para entender como as pessoas formam os seus pensamentos e desejos e a sua influência nas escolhas do dia-a-dia, devendo ser considerada por designers e empresários como uma poderosa ferramenta para compreender os indivíduos para os quais eles querem disponibilizar os seus produtos e serviços.

Entender como o designer, em seu papel de criador de interfaces entre ambiente/produto e usuário, pode contribuir, através de suas habilidades projetuais e visão diferenciada, para agregar valor às marcas e aproximá-las dos seus consumidores atuais e potenciais é essencial para empresas que buscam a constante inovação e posicionamento de destaque em seus segmentos. O mercado cada vez mais competitivo exige das companhias que tenham um enorme apreço com cada um de seus clientes, buscando não apenas agradá-los, mas surpreendê-los com seus produtos, valores e ações junto aos consumidores e a comunidade em geral. Para tanto, os conhecimentos em design, gestão estratégica, branding, marketing, inovação e tecnologia assumem um papel importante para que as marcas possam crescer sustentavelmente e realmente cativar os seus consumidores, garantindo a longevidade dessa relação.

Através do case da Heineken Experience, pudemos constatar como a criação de interfaces digitais e a preocupação com a interação humano-computador (HIC), principal área de investigação da ergonomia cognitiva, pode ser utilizada a fim de criar experiências únicas aos usuários de um produto, sistema ou, no caso, um ambiente, agregando um valor intangível à marca que proporcionou momentos tão marcantes e que levaram em conta o que cada visitante gostaria de vivenciar em seu espaço. Fica claro que mais que um museu, fábrica ou bar temático, a Heineken Experience é um verdadeiro símbolo dos valores cultivados pela empresa e os seus visitantes e consumidores conseguem enxergar e compartilhar esses valores, ganhando um novo respeito e admiração pela marca, criando um laço emocional com a empresa e seu produto. Conforme afirma Clotilde Perez, em seu livro Signos da Marca (2004), as marcas ocupam um espaço psicológico nas mentes das pessoas, sendo um conteúdo dinâmico, orgânico e flexível. Ainda segundo a autora, "O espaço perceptual da marca pode ser utilizado como um espelho que reflete o estilo de vida e os valores do consumidor atual ou potencial.".

Fica claro assim, como ações de branding e design bem elaboradas e considerando o usuário como foco podem ajudar na melhor aceitação da marca perante o público e garantir um sucesso duradouro à empresa. As organizações devem cada vez mais buscar construir momentos de interação com seus clientes e as interfaces digitais funcionam como uma importante ferramenta para atrair e engajar os consumidores, proporcionando memórias e sentimentos que vão ficar marcados e serão acessados nos momentos de escolha entre a empresa e seus concorrentes. Mais do que investir milhões de dólares em melhorar produtos que muitas vezes já são de ótima qualidade, percebe-se que vale mais a pena disponibilizar recursos para manter e conquistar aquilo que irá garantir a saúde de qualquer empresa, os seus clientes. 


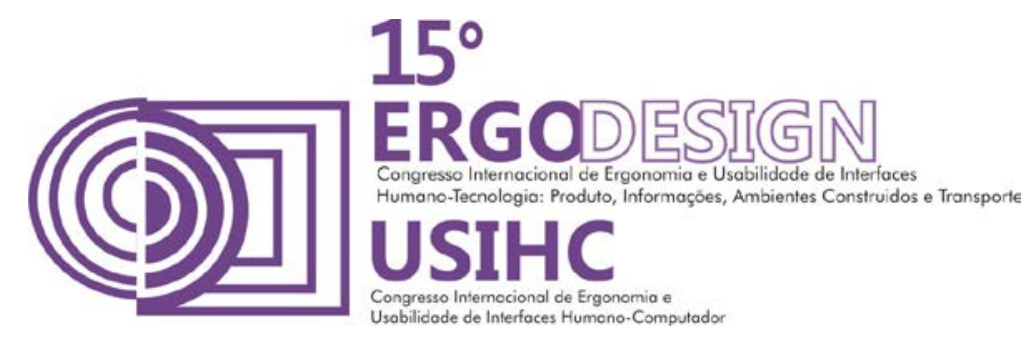

\section{$4 \quad$ REFERÊNCIAS BIBLIOGRÁFICAS}

ALLANWOOD, Gavin; BEARE, Peter. User Experience Design - Creating Designs Users Really Love. Londres, Bloomsbury Publishing, 2014.

ARRUDA, Amilton. Como a Tendência do Design Experience se Aplica Diretamente em Projetos Estratégicos. Revista Design Portfólio. Fascículo 1, 2013.

BARBOSA, Simone Diniz Junqueira; SILVA, Bruno Santana da. Interação Humano-Computador. Rio de Janeiro, Elsevier, 2011.

CAÑAS, José J.; WAERNS, Yvonne. Ergonomía Cognitiva - Aspectos Psicológicos de la Interacción de las Personas com la Tecnologia de la Infomación. Madri, Espanha, Editora Médica Panamericana, 2001.

CARVALHO, Paulo Victor Rodrigues de. In: MÁSCULO, Francisco Soares; VIDAL, Mario César (Org.). Ergonomia: Trabalho Adequado e Eficiente. Rio de Janeiro, Elsevier, 2011. cap. 9.

CHAPMAN, Stephen J. Design de Interação - Além da Interação Humano-Computador. Porto Alegre, Bookman Editora, 2011.

GOBÉ, Marc. Brandjam: O Design Emocional na Humanização das Marcas. Rio de Janeiro, Rocco, 2010.

GUTIÉRREZ, Mario A.; VEXO, Frédéric; THALMANN, Daniel. Stepping into Virtual Reality. Londres, Springer, 2008.

HILLER, Marcos. Branding: A Arte de Construir Marcas. São Paulo, Trevisan Editora, 2012.

KOTLER, Philip; KELLER, Kevin Lane. Administração de Marketing: A Bíblia do Marketing. São Paulo, Pearson Prentice Hall, 2006.

NIELSEN, Jakob. Usability Engineering. San Diego, EUA, Elsevier, 1993.

NORMAN, Donald. A. Design Emocional - por que adoramos (ou detestamos) os objetos do dia-adia. Rio de Janeiro, Rocco, 2008.

NORMAN, Donald A. O Design do Futuro. Rio de Janeiro, Rocco, 2010.

PETROSKI, Henry. A Evolução das Coisas Úteis. Rio de Janeiro, Jorge Zahar Editora, 2007.

PEREZ, Clotilde. Signos da Marca: Expressividade e Sensorialidade. São Paulo, Thomson, 2004.

SHERMAN, William R.; CRAIG, Allan B. Understanding Virtual Reality - Interface, Application and Design. San Francisco, EUA, Morgan Kaufmann Publishers, 2003.

SOARES, João Marcelo R.; SILVA, José Carlos Plácido da.; PASCHOARELLI, Luís Carlos. A Evolução da Ergonomia e sua Interface com o Design. In: PASCHOARELLI, Luís Carlos; SILVA, José Carlos Plácido da. (Org). Design Ergonômico - Estudos e Aplicações. Bauru, SP, Canal 6 Editora, 2013. p. 141-151. 